\title{
Perfil das assistentes sociais dos Institutos Federais de Educação, Ciência e Tecnologia do Brasil
}

\author{
Profile of the social workers working in the \\ Federal Institutes of Education, Science and Technology
}

Talita Prada

Assistente social do Instituto Federal de Educação, Ciência e Tecnologia da Bahia — Eunápolis-Brasil; mestre em Política Social pela Universidade Federal do Espírito Santo.

talitaprada@yahoo.com.br

Maria Lúcia Teixeira Garcia

Assistente Social. Doutora em Psicologia Social. Pós-doutora pela Universidade de Brasília (UnB). Professora Titular da Universidade Federal do Espírito Santo (UFES), Brasil. Bolsista de Produtividade do CNPq; membro do grupo de pesquisa Fênix da UFES. Coordenadora da área de Serviço Social na CAPES.

lucia-garcia@uol.com.br

Resumo: Este artigo analisa o perfil das assistentes sociais dos Institutos Federais de Educação. Pesquisa quantitativa com todas assistentes sociais dos Institutos, com análise estatística descritiva. Os resultados apontam uma profissional qualificada ( $3 \%$ são doutoras), cuja inserção intensificou-se a partir de 2009. A principal demanda da instituição aos assistentes sociais é a execução do Programa de Assistência Estudantil. A demanda por profissionais de Serviço Social nos Institutos aumentará nos próximos anos, requerendo problematizações à luz da política de educação.

Palavras-chave: Perfil. Assistente social. Institutos Federais de Educação, Ciência e Tecnologia.
Abstract: This article analyzes the profile of the social workers working in the Federal Institutes of Education. It is a quantitative research comprising all the social workers of the Institutes, together with the descriptive statistical analysis. The results show that they are qualified professionals $(3 \%$ of them have a $\mathrm{PhD}$ degree), and their insertion was intensified from 2009. The main demand of the institution to the social workers is to carry out the Student Assistance Program. The demand for social workers in the Institutes will increase in the next years, requiring some questioning in the light of education policy.

Keywords: Profile. Social worker. Federal Institutes of Education, Science and Technology. 


\section{Introdução}

$\mathrm{N}$ osso objetivo é analisar o perfil das assistentes sociais inseridas nos Institutos Federais de Educação, Ciência e Tecnologia (IFs). A relevância científica do artigo está na ausência de um estudo que caracterize nacionalmente as assistentes sociais dos IFs. Já a relevância social está no conhecimento, reflexão e compreensão do perfil das profissionais inseridas nos IFs, que tiveram significativa expansão nos últimos treze anos (2003-16), passando de 142 instituições em 2003 para 644 previstas até o final de 2016 (Brasil, 2016) e que refletem diretamente na inserção profissional e nas condições de trabalho.

Trata-se de uma pesquisa de abordagem quantitativa. Para tanto, utilizamos a análise estatística descritiva, realizada nos IFs do Brasil implantados até janeiro de 2012.

Foi enviado um questionário, por correio eletrônico, às assistentes sociais de todos os estados da federação e do Distrito Federal, identificadas no site da transparência brasileira com mais de dois anos de exercício profissional. Nossa amostra foi composta de 340 assistentes sociais. Todas foram contatadas por correio eletrônico. Destas, recebemos 158 questionários (46,06\%).

Para que a amostra fosse representativa em termos de Brasil, sorteamos três questionários do Centro-Oeste e cinco do Sudeste, de forma a garantir a aleatoriedade da amostra, e estes foram excluídos do estudo. ${ }^{1}$ Recalculamos o erro amostral para que a amostra não ficasse enviesada para nenhuma região. Com isso, nosso erro amostral ficou em $6 \%$, e a seleção obedeceu a critérios estatísticos. A Tabela 1 enfatiza a distribuição do universo da pesquisa e o retorno dos questionários.

O questionário eletrônico foi construído com a ferramenta Google Drive, pois entendemos que ela seria capaz de nos auxiliar no desenvolvimento da pesquisa devido a sua gama de possibilidades. Com ele levantamos os dados do perfil profissional. Fizemos o pré-teste do questionário com duas assistentes

1. Contamos com a assessoria de um estatístico para o planejamento do estudo e a análise dos dados. 
Tabela 1. Distribuição do universo da pesquisa e retorno

\begin{tabular}{|c|c|c|}
\hline Região & Universo & Retorno \\
\hline Norte & 42 & 15 \\
\hline Sul & 30 & 21 \\
\hline Centro-oeste & 34 & 42 \\
\hline Sudeste & 82 & 58 \\
\hline Nordeste & 152 & 150 \\
\hline Brasil & 340 & 21 \\
\hline
\end{tabular}

Fonte: Sistematização própria.

sociais, servidoras dos IFs, e em virtude de o instrumento não ter tido a necessidade de ser alterado, essas duas profissionais também compuseram a amostra da nossa pesquisa.

\section{Perfil das Assistentes Sociais dos IFs}

Os(as) ${ }^{2}$ assistentes sociais dos IFs são majoritariamente do sexo feminino (94\%), acompanhando a tendência histórica dessa profissão no Brasil. São profissionais em sua maioria jovens, com idade entre 20 e 34 anos (55\%). A ampliação do mercado de trabalho, o crescimento no número de cursos de Serviço Social e o crescimento de profissionais formadas em busca de emprego podem contribuir para a alteração no perfil encontrado pelo CFESS (2005), no qual a maioria (65\%) tinha mais de 34 anos.

2. Por termos uma amostra com $94 \%$ de assistentes sociais mulheres, pedimos licença aos $6 \%$ de profissionais homens e aos (às) nossos (as) leitores (as) para utilizarmos as formas nominais no feminino ao nos referirmos aos sujeitos desta pesquisa. 
Gráfico 1. Faixa etária das Assistentes Sociais dos IFs

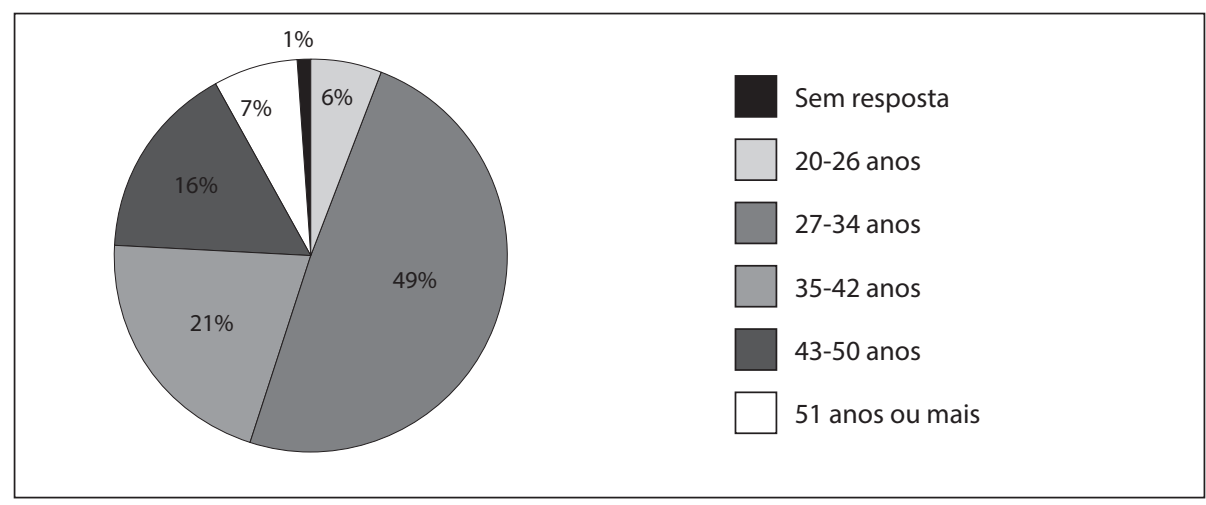

Fonte: Sistematização da autora.

Sendo jovens, mais da metade das profissionais tinha até oito anos de formadas em Serviço Social (53\%). Todas com mais de vinte anos de formação têm acima de 43 anos de idade. As profissionais de quinze a dezenove anos de formação têm, a maioria, entre 35 e 50 anos, sendo que apenas uma tem mais de cinquenta. Em relação àquelas com menos de nove anos de formação, temos majoritariamente jovens (71 assistentes sociais). A maior parte das assistentes sociais inseridas nos IFs se formaram quando tinham entre 22 e 28 anos de idade.

Gráfico 2. Tempo que se formou em Serviço Social

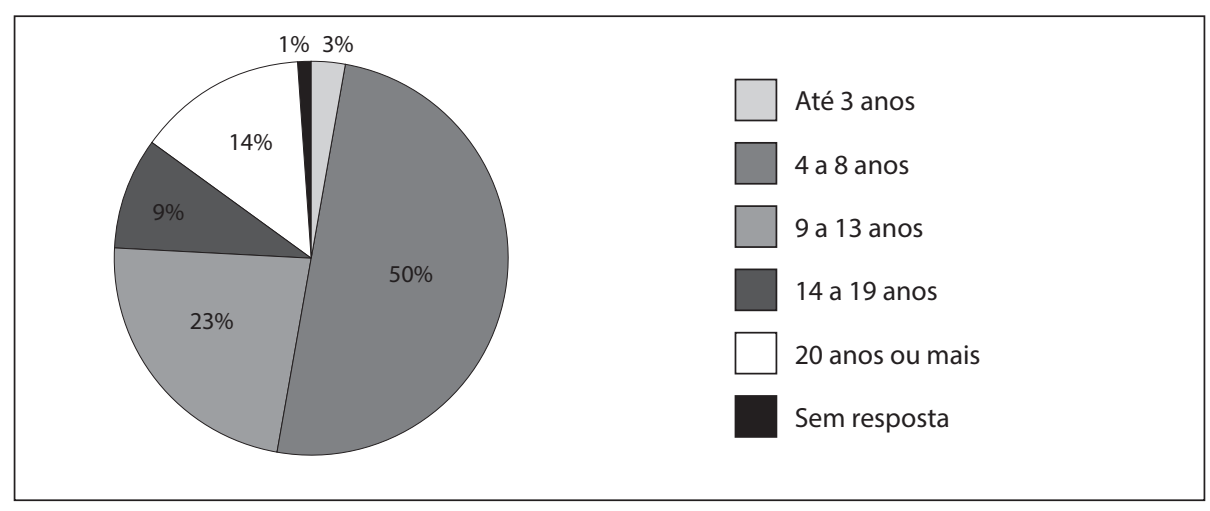

Fonte: Sistematização da autora. 
Mais da metade (63\%) das profissionais advêm das universidades públicas brasileiras (estaduais ou federais), e 36\% de universidades privadas. Quanto à modalidade de ensino, $96 \%$ foram presenciais e 3\% à distância.

Apesar disso, dados comprovam que, no Brasil, mais de 54,7\% das vagas para cursos de Serviço Social são ofertadas nas modalidades à distância, enquanto apenas $45,3 \%$ são na modalidade presencial. Outro dado importante é que dos cursos (à distância ou presencial) autorizados a funcionar entre $2003 \mathrm{e}$ 2009, 91,7\% foram de natureza privada (Pereira, 2009). Ou seja, apesar de a expansão do ensino ter possibilitado o acesso de várias camadas ao ensino superior privado, sua qualidade é questionável, e isso se baseia no dado que o acesso ao serviço público nos IFs, por meio de concurso, é em sua maioria realizado por profissionais com graduação em universidades públicas e presenciais, sendo desproporcional se comparamos a quantidade de vagas existentes nas diferentes modalidades de ensino e na oferta privada ou pública da educação. ${ }^{3}$

$\mathrm{O}$ ensino à distância tem sido alvo de debate do conjunto CFESS/Cress, dado sua questionável qualidade. Corroboram com isso diversos documentos que demonstram a incompatibilidade entre o ensino à distância e o Serviço Social, em virtude do descumprimento das diretrizes curriculares e condições fundamentais para que o estudante possa ter uma educação de qualidade (CFESS et al. 2011). Entretanto, nosso estudo indica que o percentual de profissionais com formação em cursos de EAD vem adentrando o mercado de trabalho (nos IFs são 3\% dos assistentes sociais), e isso requer novas discussões e ações que garantam formação continuada de qualidade após a graduação.

No que diz respeito à idade, quando cruzamos os dados referentes à instituição de formação e a idade da profissional, identificamos que as assistentes sociais com formação na modalidade ensino à distância fazem seu curso mais velhas (entre 24 e 40 anos) e possuem pouco tempo de formadas, ou seja, difere do perfil geral apresentado anteriormente. Mas esse dado não difere do perfil majoritário dos estudantes de ensino à distância, que têm mais de 24 anos

3. Em agosto de 2011 havia 358 cursos de graduação autorizados pelo MEC, sendo dezoito de ensino à distância (EAD), que ofertaram, no mesmo ano, 68.742 vagas. Já os 340 cursos presenciais ofertaram 39.290 vagas. As matrículas em cursos de Serviço Social se distribuíam assim em 2011: na modalidade EAD, 80.650 matrículas; na modalidade presencial, 72.019 matrículas (Iamamoto, 2014). 
e geralmente se beneficiam da flexibilidade dos horários para que seja possível a conciliação de trabalho e estudos (Tonegutti, 2010; Pereira, 2007; CFESS et al., 2011; Azevedo, 2009).

No que se refere à região de formação, a maioria das profissionais se formou na região em que trabalha. Contudo, identificamos que $28 \%$ delas participaram de um processo migratório dentro do estado ou da própria região. Tal migração ocorreu ou para ter acesso à educação superior, para assumir cargo público, ou até para ambas as situações.

Com o cruzamento dos dados da região em que trabalha com a região em que se formou, identifica-se que no Sudeste não há profissionais de outras regiões trabalhando. Uma das possibilidades é a diversidade de instituições de educação superior na região de formação, o que resulta em vagas para inserção no mercado de trabalho (historicamente essa região recebeu maiores investimentos em infraestrutura para o desenvolvimento e apresenta maior concentração de universidades federais e estaduais). ${ }^{4}$

Nas regiões Sul, Sudeste e Centro-Oeste temos profissionais que se deslocaram para outras regiões para a inserção nos IFs do Norte e Nordeste. Essas regiões apresentaram a maior empregabilidade de assistentes sociais, o que pode ter se dado em virtude da expansão dos IFs, pelas menores possibilidades de acesso ao ensino superior e sua qualidade, dada a expansão territorial e a oferta de vagas. No que se refere ao Sul e ao Centro-Oeste, apesar de também ter demandado servidores para os IFs, nessas regiões o acesso às instituições de formação superior é facilitado por fatores como maior oferta de vagas e densidade demográfica. Destaca-se que na região Sul, em particular, há grande quantidade de IFs sem assistentes sociais no quadro técnico, o que pode denotar que futuramente haverá uma expansão das vagas para essa região.

A busca por educação continuada e qualificação profissional está presente no perfil das profissionais aqui estudadas. Identifica-se que a quase totalidade delas (96\%) possui pós-graduação lato ou stricto sensu (64\%, especialização;

\footnotetext{
4. A quantidade de habitantes por instituição de educação superior (IES) nas regiões brasileiras são assim distribuídas: Norte - 104.371; Nordeste - 122.875; Centro-Oeste - 59.822; Sudeste — 69.459; Sul — 70.403. Dessas IES, $8 \%$ são universidades; $5 \%$, centros universitários; $2 \%$, IFs e Cefets; $85 \%$, faculdades. Sendo 4\% instituições federais; $5 \%$, estaduais; 3\%, municipais; $88 \%$, privadas (Brasil, 2013).
} 
$29 \%$, mestrado; $3 \%$, doutorado) e que as demais (4\%) cursavam algum tipo de especialização. Esse dado diverge da caracterização nacional, que apresenta que $55 \%$ das profissionais possuem apenas a graduação; $36 \%$, especialização; $6 \%$, mestrado; $1 \%$, doutorado (CFESS, 2005). Podemos inferir que em decorrência da estruturação da carreira federal, as servidoras e servidores dos IFs têm incentivos financeiros à qualificação. Destarte, o plano de carreira do Serviço Público Federal para técnico administrativo em educação possibilita o incentivo à qualificação de $30 \%$ para profissionais com especialização lato sensu, $52 \%$ com mestrado e $72 \%$ com doutorado, o que é um fator adicional de incentivo à qualificação profissional. Cabe destacar o percentual de 3\% de assistentes sociais com doutorado (três vezes superior aos dados do CFESS).

A expansão dos programas de pós-graduação stricto sensu e o interesse pelo desenvolvimento de pesquisas e pela área acadêmica evidenciam dois aspectos: a) a pesquisa como componente indissociável do trabalho do assistente social (Iamamoto, 2005); b) o processo de aprimoramento continuado profissional. No caso da pós-graduação na área de Serviço Social, esta é acadêmica e permite aos seus discentes o aprofundamento em temas relevantes para a compreensão da realidade social.

Ficam-nos as questões: Será que a possibilidade de pontuação de pós-graduação lato ou stricto sensu para a titulação em concursos públicos e a dificuldade de inserção imediata, após a formação, no mercado de trabalho também não podem ter motivado a realização desses cursos? Dado o perfil de qualificação das profissionais dos IFs, será que o trabalho profissional difere das assistentes sociais com menor qualificação, ou a qualificação é utilizada apenas como exercício de retórica e progressão na carreira? A qualificação possibilita o enfrentamento das condições de trabalho elencados como precarizadas? De que forma?

Como constituinte e constitutiva da profissão, a dimensão investigativa apareceu no perfil dessas profissionais por meio de grupos de estudos dos quais $32 \%$ participavam. Apesar de não representar a maioria, é um dado significativo, considerando as inúmeras demandas apresentadas a essas profissionais. Isso aponta que o direito à liberdade na realização de estudos e pesquisas, resguardado os direitos de participação de indivíduos ou grupos 
envolvidos em seus trabalhos e do aprimoramento intelectual contínuo (Brasil, 1993), faz parte do trabalho em algumas instituições. É válido destacar que por ser um espaço sócio-ocupacional inscrito na política de educação, a existência de grupos de estudos nesses espaços é um diferencial para a participação da profissional.

Em relação à temática dos grupos, a maior parte está relacionada ao estudo da política de educação, seguida de temáticas transversais que perpassam a política educacional, como as questões de gênero e inclusão. A participação em grupo de estudos com a temática peculiar ao Serviço Social também esteve presente como: políticas públicas, políticas sociais, movimentos sociais, trabalho e juventude, lazer, método em Marx, sociologia econômica e envelhecimento humano.

Em relação ao tempo de trabalho, $67 \%$ das assistentes sociais tinham mais de dois anos de exercício profissional e 33\% tinham menos de dois anos na instituição. Daquelas com mais de dois de trabalho nos IFs, $71 \%$ têm até cinco anos. Ou seja, a maioria iniciou suas atividades após a aprovação do Programa Nacional de Assistência Estudantil ou iniciou um pouco antes da aprovação, um período em que a demanda por políticas de permanência já era vigente no cenário dos IFs.

Apesar de os IFs serem historicamente uma instituição centenária, apenas $7 \%$ das profissionais da nossa amostra têm doze anos ou mais de exercício profissional. Esses dados revelam duas questões: a primeira é que a expansão das instituições possibilitou a abertura de algumas vagas para a categoria profissional; a segunda (e não menos importante) é que o acesso de mais de $71 \%$ das profissionais se deu no período de aprovação do Programa de Assistência Estudantil, ou seja, essa profissional adentrou no Instituto com uma clara demanda institucional de atender aos estudantes com auxílios e bolsas estudantis.

Em relação às profissionais que apresentam doze anos ou mais de trabalho nos IFs, todas têm mais de duas décadas de formação e a idade superior a 43 anos. Apenas $12 \%$ das profissionais tiveram o ingresso no IF como o primeiro emprego, enquanto a maioria, $88 \%$, já havia trabalhado anteriormente em outras áreas. Essas profissionais trazem experiências na assistência social e na saúde, dois importantes campos de atuação das assistentes sociais brasileiras. 
Gráfico 3. Tempo de trabalho no IF

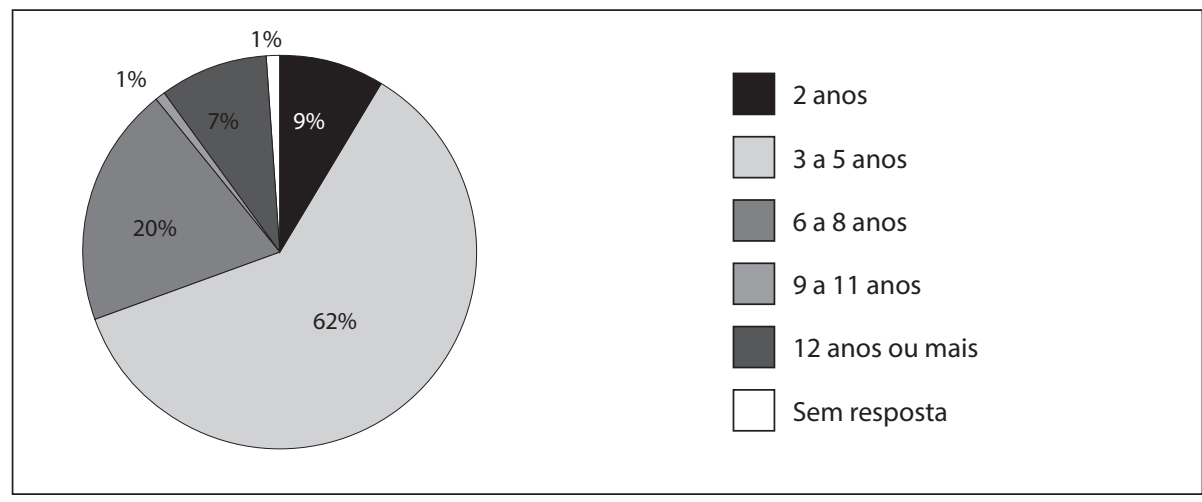

Fonte: Sistematização da autora.

Esse processo de transição de trabalho nas duas políticas não deixa de refletir os espaços de trabalho abertos à categoria. A Política Nacional de Assistência Social - PNAS tem demandado profissionais, dentre eles assistente social, que a política garante como profissional obrigatório na composição das equipes de Proteção Social Básica e Proteção Social Especial de média e alta complexidade para o funcionamento dos serviços. Assim, também a expansão de vagas para as assistentes sociais tem ocorrido com os IFs a partir de 2010, com a aprovação do PNAES.

Além dessas duas áreas predominantes, também tivemos inserção na educação, habitação, área jurídica e terceiro setor. Tais dados mostram que as profissionais, dada sua formação, se inserem nas mais diversas áreas relacionadas à execução de políticas públicas e também naquelas em que a atividade que desenvolvem é privativa do Serviço Social.

No que diz respeito à carga horária, temos que $44 \%$ trabalham trinta horas semanais, direito previsto por lei em 2010, com a alteração da Lei n. 8.662/93 (Brasil, 2010b). Todavia, ressalta-se que uma parcela dessas profissionais teve o direito garantido sem que houvesse a redução salarial, conforme prevê a lei, ainda que o cargo de técnico administrativo/assistente social seja de quarenta horas semanais. Essa conquista é parcial, já que a carga horária que havia sido alterada pelo Ministério do Planejamento, Orçamento e Gestão (MPOG), por 
meio de portaria (Brasil, 2010c; Brasil, 2011), logo em seguida foi revogada, excluindo as assistentes sociais das profissionais que têm carga horária reduzida (Brasil, 2012).

O cumprimento da carga horária de trinta horas semanais nos IFs ocorre principalmente em virtude do Decreto n. 1.590 (Brasil, 1995), que permite às servidoras e servidores da administração pública federal direta, das autarquias e fundações que trabalhem em turnos ininterruptos, igual ou superior a doze horas, que cumpra carga horária de seis horas diárias e trinta horas semanais. Apesar disso, o processo de implementação do ponto eletrônico nas instituições federais ameaça a garantia das trinta horas à profissional, uma vez que é baseado em acordos internos, não é formalizado pelo MPOG, e em algumas instituições com somente uma profissional, ela é obrigada a trabalhar quarenta horas.

Por ser efetivado apenas por meio de acordos institucionais, temos, por outro lado, profissionais que solicitaram a redução da carga horária para vinte horas semanais (1\%) e em virtude de o direito ser garantido apenas internamente, mas a carga horária do cargo não ter sido alterada, em vez de a redução do salário ter sido de um terço, correspondeu a $50 \%$.

Gráfico 4. Área de trabalho antes do ingresso no IF

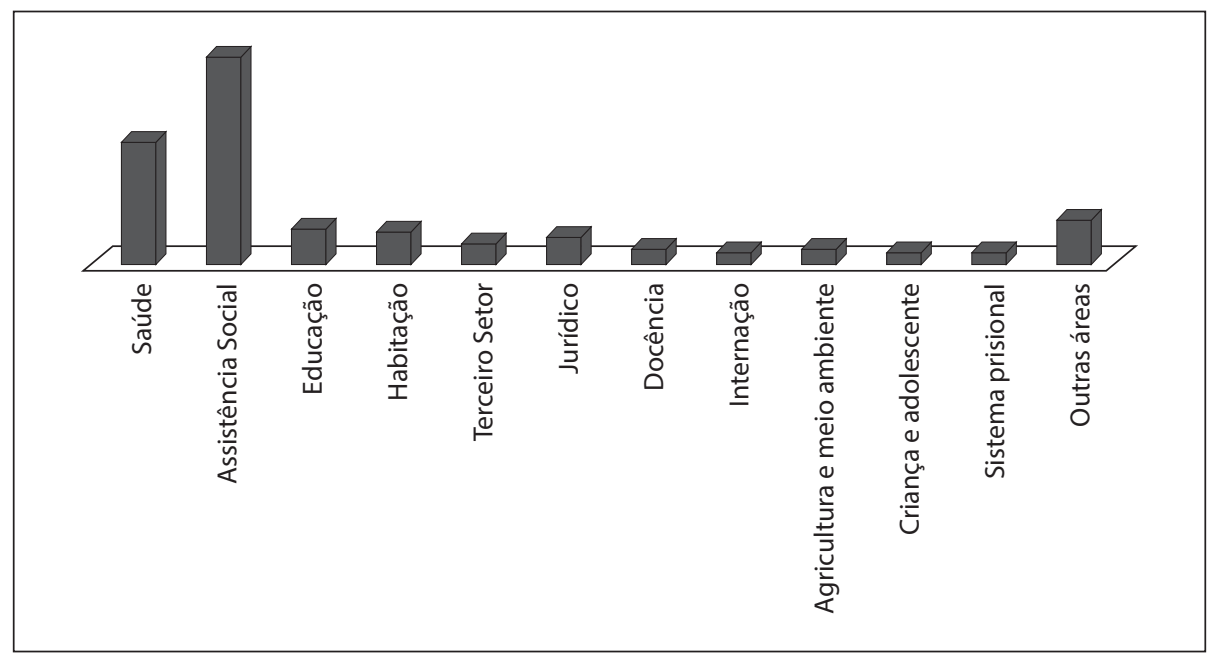

Fonte: Sistematização da autora. 
Como já alertados por Fernandes (2005), a violação das leis no Estado brasileiro é presente desde a Independência. A redução da carga horária da assistente social é uma luta da categoria. Contudo, vale refletirmos sobre como tem se dado tal redução, uma vez que em parte dos espaços sócio-ocupacionais ela não correspondeu ao aumento do quadro de profissionais. Isso acarretou sobrecarga de trabalho profissional, já que a assistente social tem que desenvolver todas as atividades que desenvolvia, antes em quarenta horas, agora em trinta horas, ou seja, a demanda que extrapola a carga de trinta horas semanais na maioria das vezes fica sob a responsabilidade individual da assistente social.

No quadro institucional, ainda temos $53 \%$ das assistentes sociais que trabalham quarenta horas semanais. Destas, $23 \%$ ocupam cargo de direção ou têm função gratificada, o que poderia justificar o exercício de quarenta horas semanais, por prever por lei a dedicação exclusiva (Brasil, 1990).

Porém, daquelas que têm função gratificada, quatro trabalham trinta horas semanais; 28 , quarenta horas semanais; $1 \%$, mais de quarenta horas semanais. Das que trabalham quarenta horas, 52 não exercem função gratificada ou cargo de direção $(34,66 \%)$. Ou seja, apesar de termos uma lei federal que aprova a redução da carga horária da profissional para trinta horas, o governo federal, por meio do MPOG, é o primeiro a violar tal lei, já que a execução das trinta horas está relacionada a uma questão interna dos IFs ou à execução do Decreto n. 1.590 (Brasil, 1995), e não propriamente a um compromisso federal em se efetivar a lei, como identificamos que o próprio cargo é de quarenta horas semanais e não sofreu nenhuma alteração legal com a aprovação das trinta horas.

O cruzamento dos dados da carga horária de quarenta horas das profissionais sem função gratificada ou cargo de direção ${ }^{5}$, com a região de trabalho, nos permitiu identificar que no Sudeste está a maior parte das profissionais que cumprem quarenta horas, totalizando vinte profissionais; no Centro-Oeste, oito; no Sul, cinco; no Norte, sete; no Nordeste, doze.

Os dados sobre a existência de outro vínculo empregatício revela que a maioria ( $87 \%$ ) possui apenas o vínculo com o IF, mas $12 \%$ têm outro vínculo, dado próximo ao perfil apresentado pelo CFESS (2005), em que 11\% tinham

5. Função gratificada e cargo de direção são gratificações ao servidor público federal efetivo que ocupa cargo de confiança. 
outro vínculo empregatício. Dessas profissionais, uma trabalha vinte horas no IF; nove trabalham trinta horas; sete, quarenta horas, e uma, além de exercer FG ou CD e trabalhar mais de quarenta horas semanais, ainda possui outro vínculo empregatício. Cabe aqui destacar a sobrecarga de trabalho a que estão expostos esses $12 \%$. Para todas, o trabalho se torna alienado, fetichizado, negando o desenvolvimento humano. Contudo, o assalariamento provoca a ilusão, ou alienação, de que o salário que recebem faz juz ao trabalho (Lessa e Tonet, 2011). Essa necessidade de exercer outras atividades fora o trabalho nos IFs tende a provocar desgaste profissional, bem como risco à convivência social e à saúde das trabalhadoras.

A expansão dessas instituições possibilitou que se ampliasse o mercado para as assistentes sociais nesses espaços. Tal ampliação deve ter continuidade nos próximos anos, já que por meio do cruzamento dos dados dos sites dos IFs (que dispõe sobre os IFs implantados) e os dados do site da transparência brasileira (que dispõe sobre os servidores públicos federais e seus locais de trabalho), podemos identificar, pela elaboração de um mapa, a existência de muitos institutos que não têm em seu quadro de servidores essa profissional. O mapa também evidencia a concentração de IFs por regiões do país. A região Norte ganha destaque pela sua área e também pela desproporcional quantidade de IFs. Já no Sul é o inverso que ocorre, uma vez que há a concentração de IFs em uma pequena área.

Sobre isso, identificamos que até janeiro de 2015 tínhamos 570 institutos distribuídos em todo o Brasil. Deste total, 351 instituições já possuem pelo menos uma assistente social, sendo que 219 não possuem nenhuma. Logo, apesar da quantidade de IFs sem assistentes sociais, hoje temos que a maioria, $62 \%$, contam com essa servidora. Nas regiões Norte e Sul, a presença dessa profissional é menor, ao mesmo tempo em que há um equilíbrio entre os IFs que têm e não têm assistente social nas regiões Centro-Oeste, Nordeste e Sudeste.

Dos institutos que têm assistentes sociais, quase a metade (48\%) conta apenas com uma profissional no local específico de trabalho, que pode ser no trabalho relacionado ao estudante, ao servidor ou à comunidade. Destaca-se que $47 \%$ têm mais de uma profissional no mesmo local de trabalho. Desses $47 \%$, temos que $27 \%$ das instituições têm dois profissionais; $5 \%$, três; $7 \%$, quatro; $8 \%$, cinco ou mais. 
Figura 1. Mapa do Brasil com a distribuição de IFs

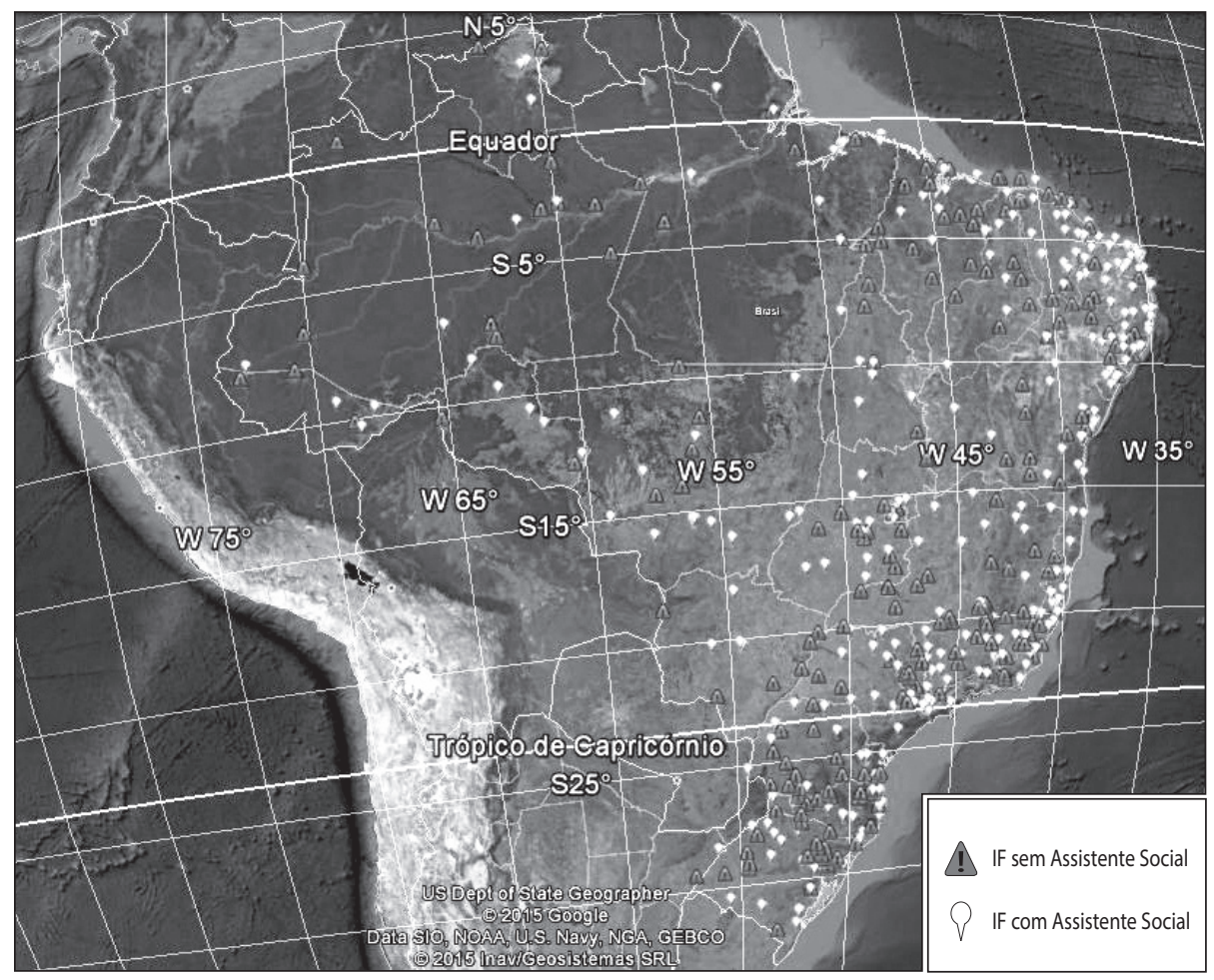

Fonte: Sistematização da autora.

No que se refere à quantidade de discentes, metade dos IFs $(51 \%)$ tem até $1.200 ; 14 \%$, de 1.201 a $2.400 ; 4 \%$, de 2.401 a $3.600 ; 1 \%, 3.600$ a 4.800 ; $25 \%$ possuem mais de 4.800 alunos e são instituições mais antigas em relação às instituições menores, que são as advindas do processo de expansão e que estão iniciando seu processo de implantação e implementação dos cursos nos níveis médio, subsequente e superior e pós-graduação. À medida que se consolidam, expandem seus cursos, suas matrículas e dão continuidade ao seu crescimento.

Todo esse processo de expansão, tanto de IFs como de espaços de trabalho para a assistente social, não esteve isento de contradições. Isto porque ao mesmo tempo em que houve investimento na infraestrutura física para a expansão 
dos institutos, não houve o acompanhamento no crescimento das equipes para o desenvolvimento das atividades no interior das instituições.

Posteriormente ao processo de expansão física das instituições iniciado em 2005 e em andamento, foram aprovadas as políticas de assistência estudantil em 2010 (Brasil, 2010a) e de cotas em 2012 (Brasil, 2012). Tais políticas foram a razão da contratação de assistentes sociais em muitos institutos. Apesar disso, o processo de expansão não foi acompanhado pela estruturação de todas as equipes técnicas, havendo divergências sobre a presença de profissionais entre os campi dos próprios institutos.

Houve o aumento das demandas para as assistentes sociais e outros profissionais, dada as lutas por políticas de assistência estudantil, que historicamente foram demandadas pelos movimentos sociais de estudantes às instituições, mas que não eram garantidas como direito. Outra questão é a limitada quantidade de profissionais das várias áreas de conhecimento destinados a esses institutos em expansão. Há registros de campi que funcionam somente com Programa Nacional de Acesso ao Ensino Técnico e Emprego (Pronatec); turmas que ficam meses sem professores; institutos sem assistentes sociais em que os recursos de assistência estudantil são devolvidos ou são executados por pedagogos; outros que devolvem anualmente recursos por não terem servidores responsáveis para dar andamento a processos como, por exemplo, os recursos do Fundo Nacional de Desenvolvimento da Educação para a oferta de merenda escolar. Ou seja, por vezes os institutos se expandiram, a demanda aumentou, mas não houve a correspondente contratação de profissionais.

É claro que, em se tratando de uma política de permanência, os investimentos por vezes se limitam à concessão de auxílios financeiros, sendo silenciadas as demais medidas necessárias para a permanência do discente. Isso se dá institucionalmente em virtude da dificuldade de contratação de profissionais e códigos de vaga para o exercício dos cargos necessários. Logo, a instituição prioriza algumas ações em detrimento de outras, tendo em vista as demandas emergentes que são chamadas a responder. Quando o assunto é a pobreza, há a concessão das bolsas e auxílios de caráter seletivo e focalizado, que auxiliam na minimização dos impactos da pobreza no processo acadêmico. Porém quando as questões perpassam a pobreza, mas não se resolvem por meio apenas da 
concessão dos auxílios, e sim por outras medidas em que há a necessidade de intervenção de outros profissionais e/ou serviços, a intervenção acaba sendo mais restrita.

Essa conjuntura de precarização do trabalho articulada com a degradação das condições de sobrevivência do trabalhador reflete nas condições de vida da população, no exercício profissional das assistentes sociais e tem desafiado cotidianamente o trabalho nos IFs.

A sobrecarga de trabalho apareceu como uma dificuldade para a realização das atribuições profissionais. Esse cenário adverso requer compromisso institucional e ético-político para revertê-lo. Outra constatação da importância do compromisso ético-político foi o destaque ao desconhecimento do trabalho do Serviço Social no interior da instituição, reflexo da restrita inserção profissional existente até se efetivar a expansão das instituições e da própria ausência dos projetos de intervenção. Apesar disso, o desconhecimento do trabalho pode ser enfrentado com a elaboração de projeto profissional que esclareça os objetivos, competências profissionais, atividades privativas e que reconheça o espaço de trabalho para possibilitar à instituição o reconhecimento do exercício profissional, buscando assim oferecer condições adequadas à sua execução.

[...] a necessidade de clareza do projeto de trabalho coloca-se sob vários ângulos. Um deles é o de que o assistente social, ao ser contratado, identifica como trabalho seu naquele espaço sócio-ocupacional. Nesse ângulo, há o reconhecimento, por parte do profissional, daquilo que the compete. Rompe-se, assim, com uma característica que, em muito, contribui para a desqualificação profissional, ou seja, aquela em que os assistentes sociais reproduzem o projeto institucional como seu projeto. É certo que o projeto da instituição compõe o arsenal de conhecimento a ser levado em conta pelo assistente social, mas não encerra aquilo que a profissão tem a oferecer. Ao assumir um espaço sócio-ocupacional, há que se estabelecer, com clareza, o que a profissão tem a oferecer como subsídio para o atendimento das demandas que competem à instituição satisfazer, resguardando-se as características da natureza pública ou privada, mas mantendo-se o compromisso com estratégias que traduzem o trabalho do assistente social como espaço coletivo e democrático. (Couto, 2009, p. 653) 
No trabalho desenvolvido pela assistente social dentro dos IFs, seja com estudante, servidor ou comunidade, o projeto de intervenção profissional é um importante instrumento para concretizá-lo nesse espaço repleto de contradições, as quais são advindas de um processo de expansão dos institutos, inserida no contexto de expansão de políticas marcadas pela financeirização e pela restrição de direitos.

A elaboração de um projeto de intervenção profissional consiste na materialização de um trabalho. Faz parte de uma intervenção que prima pela dimensão investigativa para contribuir na compreensão das condições de vida, de trabalho e de educação e requer a adoção de procedimentos sistemáticos previamente pensados de apreensão da realidade social para além da empiria e sua aparência, constando do projeto de intervenção profissional (CFESS, 2013) e que deve ser pensado no interior dos IFs. Nesse sentido, o foco na assistência estudantil não é um problema, mas sim fim que se tem que buscar para que essa atuação seja desenvolvida de modo que seja realizada com qualidade, tendo em vista sua importância na efetivação dos direitos estudantis na comunidade acadêmica.

Destarte, o projeto de intervenção buscará a identificação das requisições para a intervenção profissional e a avaliação se essa intervenção responder às necessidades sociais que, demandadas, devem ser privilegiadas nos processos de trabalho (Couto, 2009). Buscamos, assim, identificar se as profissionais têm conseguido elaborar o projeto de intervenção profissional para a concretização de sua tarefa e no intuito de, como aponta Couto (2009), fugir de improvisações, planejando o trabalho para dar sentido teleológico.

Das assistentes sociais dos IFs, 35\% têm projeto de intervenção profissional, ou seja, essas profissionais (apesar de todo o contexto que envolve o trabalho profissional) conseguiram parar para refletir sobre suas práticas e intervenção profissional. Baseados neste, podem enfrentar as demandas institucionais que não correspondem a suas competências e resistir a esse contexto para a proposição de outras práticas, bem como buscar formas de superação tanto da visão institucional sobre o Serviço Social, como no sentido de valorizar a atuação profissional. Esse processo reflete também a articulação das profissionais no interior dos campi para a construção do seu projeto profissional que podem 
atingir a articulação entre os campi. Apesar de 59\% das profissionais não possuírem projeto de intervenção profissional (6\% não responderam), as entrevistadas de todas as regiões destacaram que há (ou já houve) encontros entre elas para que seja pensada a prática no interior das instituições.

Como resultado dessas articulações, as profissionais do IFBA têm um documento elaborado coletivamente pela categoria desde 2008 que enumera as atribuições profissionais das diversas áreas de atuação no interior da instituição como: assistência estudantil, necessidades especiais, extensão comunitária, saúde e gestão de pessoas.

Sem o processo reflexivo sobre a prática profissional, o desafio para superar o contexto adverso passa a ser maior, dado que os limites da prática profissional emergente não possibilita a superação de ações institucionais imediatas. Logo, não ter um projeto de intervenção profissional implica desqualificação da profissional com a reprodução do projeto institucional como projeto do Serviço Social (Couto, 2009).

Apesar disso, foi citada a existência de planejamento escrito das atividades e que só foi executado em parte. Ou seja, não foi possível cumprir tudo o que fora planejado. Dentre os fatores que impediram a efetivação das ações do planejamento estavam as greves, a sobrecarga de trabalho e as questões emergenciais.

Apesar de as greves aparecerem como um entrave para a execução do planejamento, há o entendimento e a defesa de que elas fazem parte do processo de luta em prol de melhorias nas condições de trabalho e na busca de conquistas, tanto para o trabalhador quanto para a educação como um todo. O processo em que se dá a realização do trabalho sobrecarrega as profissionais e dificulta a reflexão sobre a intervenção que poderá possibilitar a efetivação dos direitos sociais.

Outra questão apontada foram as condições para a realização do trabalho. Espaço físico inadequado e infraestrutura precária refletem, além da precariedade da expansão, um despreparo institucional para receber essas profissionais, uma vez que a educação não é um campo tradicional de trabalho das assistentes sociais, e sim de outros profissionais que já legitimaram esse espaço, como os professores e pedagogos. Ainda assim, em virtude do comprometimento ético-político, mesmo enfrentando os reveses dessa expansão, há a reflexão sobre o 
trabalho e a necessidade de materializá-lo por meio do projeto profissional, de forma superar o foco nas demandas institucionais, o que tem sido desafiador em virtude das contradições desse espaço.

\section{Considerações finais}

Neste artigo, identificamos dados a respeito do perfil profissional das assistentes sociais e de inserção nos IFs que apontam questões importantes para reflexão sobre essas profissionais.

Identificamos um perfil diferenciado, se comparado com os dados da pesquisa do CFESS (2005). Aqui as profissionais são, em sua maioria, jovens, formadas em universidades públicas e presenciais. A maior parte $(96 \%)$ tem algum tipo de especialização, e $32 \%$ participam de grupo de estudos no intuito de possibilitar a continuidade do aprimoramento intelectual relacionados em sua maioria à temática educativa. Outro fator de destaque é que a profissional passa a fazer parte do quadro institucional principalmente em virtude das demandas por políticas de assistência estudantil e principalmente com a expansão do número de IFs.

Tais profissionais possuem, em sua maioria, experiência profissional nas políticas de Assistência Social e Saúde, que, em virtude da aprovação de normativas e programas, tem demandado o trabalho delas. Nota-se ainda que apesar da regulamentação das trinta horas semanais para as assistentes sociais, nos IFs essa garantia ainda se vincula a acordos institucionais internos, não se efetivando na maioria das instituições.

Entre os IFs com assistentes sociais no seu quadro técnico, identificamos um discurso recorrente de sobrecarga de trabalho, em virtude da não adequação do número de profissionais ao número de discentes que demandam assistência estudantil, foco maior do trabalho profissional. Essa sobrecarga de trabalho não é exclusiva da assistente social, mas atinge outros profissionais e setores, já que o número de servidores não acompanhou a expansão de matrículas, devido aos restritos recursos, ao enxugamento do quadro de servidores e à busca de eficiência, eficácia e produtividade no interior dos campi. 
A assistente social, além de ter que assumir o que lhe é privativo ou competência profissional, ainda necessita assumir outras atividades administrativas para que haja continuidade na execução do PNAES, já que é (pela gestão) e se sente, na maioria das vezes, responsabilizada por toda a sua execução.

Esse fato também recai sobre a questão de o Serviço Social nos IFs ter sua inserção majoritária após o processo de expansão institucional, já que anteriormente havia restrita quantidade de profissionais inseridas, desenvolvendo uma diversidade de tarefas. Com a expansão, ocorre a inserção da maioria das profissionais que hoje trabalham no IF e se tem a demanda por entender o que faz essa profissional na instituição. Pelo entendimento que se tem da prática profissional por parte dos gestores, por vezes eles tornam as demandas por execução orçamentária prioritária sobre as demais, já que elas têm que ser atendidas, ainda que não haja profissionais suficientes para tanto.

Nesse sentido, é importante a elaboração de um projeto de intervenção profissional. É preciso que estejam claras as atribuições e competências profissionais para que a profissional possa se posicionar contrariamente às demandas institucionais que não corroboram para a efetivação e a ampliação dos direitos. Apesar desse contexto contraditório que se acirra a todo momento, uma parcela significativa de profissionais tem elaborado seu projeto de traba1ho. No IFBA há um documento elaborado pelas profissionais sobre suas atribuições e competências na PAE, na Saúde, na intervenção junto a pessoas com necessidades educacionais específicas, na gestão de pessoas e na extensão, que vem para fortalecer a prática profissional e minimizar os impactos da conjuntura institucional.

Deve-se ressaltar que no processo de expansão institucional, por estar ainda inconcluso, a demanda por profissionais tende a crescer nos próximos anos em virtude do aumento da quantidade de discentes nas instituições e em decorrência de grande parte delas não ter ainda no quadro nenhuma profissional.

Por fim, tal expansão no mercado de trabalho para a assistente social nos IFs indica a relevância na continuidade dos estudos e reflexão sobre o trabalho profissional nesse espaço, que, apesar de não ser novo, tem tido maior expressão a partir de 2009. Nesse sentido, diversas são as questões e indagações que ainda carecem de respostas e reflexões necessárias ao enfrentamento dos desa- 
fios institucionais cotidianos a ser vencidos na luta pela efetivação do nosso projeto ético-político profissional, consolidando, assim, os direitos da classe trabalhadora. Mais que um ponto final, é necessário continuar os estudos e resistir frente ao ataque cotidiano de direitos sofridos pela classe trabalhadora $\mathrm{e}$ aqui expresso no perfil profissional da assistente social e na expansão dos IFs.

\section{Recebido em 18/7/2016 - Aprovado em 15/2/2017}

\section{Referências bibliográficas}

AZEVEDO, D. R. de. Educação à distância: estudo comparativo do perfil e motivações dos alunos das instituições de ensino superior e das organizações corporativas. Dissertação (Mestrado em Ciências Sociais) — Programa de Pós-Graduação em Ciências Sociais. Pontifícia Universidade Católica do Rio Grande do Sul, Porto Alegre, 2009.

BRASIL. Lei n. 8112, de 11 de dezembro de 1990. Dispõe sobre o regime jurídico dos servidores públicos civis da União, das autarquias e das fundações públicas federais. Brasília, 1990. Disponível em: <http://www.planalto.gov.br/ccivil_03/leis/L8112cons. htm>. Acesso em: 13 ago. 2013.

Lei n. 8.662, de 7 de junho de 1993. Lei de Regulamentação Profissional do Assistente Social. Brasília, 1993. Disponível em: <https:/www.google.com.br/ webhp?sourceid=chrome-instant\&rlz=1C1GGGE_pt-BRBR606BR606\&ion=1\&espv= $2 \& \mathrm{ie}=\mathrm{UTF}-8 \# \mathrm{q}=\mathrm{lei}+\mathrm{de}+$ regulamenta $\% \mathrm{C} 3 \% \mathrm{~A} 7 \% \mathrm{C} 3 \% \mathrm{~A} 3 \mathrm{o}+\mathrm{do}+$ assistente + social $>$. Acesso em: 13 ago. 2013.

Decreto n. 1.590, de 10 de agosto de 1995. Dispõe sobre a jornada de trabalho dos servidores da administração pública federal direta, das autarquias e fundações federais, e dá outras providências. Brasília, 1995. Disponível em: <www.planalto.gov. br/ccivil_03/decreto/d1590.htm>. Acesso em: 20 jan. 2015.

. Decreto n. 7.234, de 19 de julho de 2010. Dispõe sobre o Programa Nacional de Assistência Estudantil. Brasília, 2010a. Disponível em: <http://www.planalto.gov. br/ccivil_03/_Ato2007-2010/2010/Decreto/D7234.htm>. Acesso em: 20 nov. 2013. 
BRASIL. Lei n. 12.317, de 26 de agosto de 2010. Altera a Lei n. 8662/93 e institui a carga horária de trinta horas para assistente social. Brasília, 2010b. Disponível em: $<$ http://www.planalto.gov.br/ccivil_03/_Ato2007-2010/2010/Lei/L12317.htm>. Acesso em: 20 nov. 2013.

. Ministério do Planejamento, Orçamento e Gestão. Portaria n. 3.353, de 20 de dezembro de 2010. Brasília, 2010c.

. Ministério do Planejamento, Orçamento e Gestão. Secretaria de Recursos Humanos. Orientação Normativa 1 , de $1^{\circ}$ de fevereiro de 2011. Diário Oficial da União, Brasília, 2011.

. Ministério do Planejamento, Orçamento e Gestão. Secretaria de Gestão Pública. Portaria n. 97, de 17 de fevereiro de 2012. Diário Oficial da União, Brasília, 2012.

. Lei n. 12.711, de 29 de agosto de 2012. Dispõe sobre o ingresso nas universidades federais e nas instituições federais de ensino técnico de nível médio e dá outras providências. 2012. Disponível em: <http://www.planalto.gov.br/ccivil_03/_ato20112014/2012/lei/112711.htm>. Acesso em: 13 ago. 2014.

. Organização das Nações Unidas para a Educação, Ciência e Cultura. Conselho Nacional de Educação. Projeto CNE/Unesco 914BRZ1136.3 Desenvolvimento, aprimoramento e consolidação de uma educação nacional de qualidade. Produto 1 Panorama e diagnóstico da oferta e qualidade da educação superior brasileira. São Paulo, 2013.

. Ministério da Educação. Expansão da rede federal. 2016. Disponível em: $<$ http://redefederal.mec.gov.br/expansao-da-rede-federal $>$. Acesso em: 14 jul. 2016.

CFESS. Assistentes sociais no Brasil: elementos para o estudo do perfil do profissional. Brasília: CFESS, 2005.

. Subsídios para atuação de assistentes sociais na política de educação. Brasília, n. 3, 2013 .

et al. (Orgs.). Abaixo a censura: sobre a incompatibilidade entre graduação à distância e Serviço Social. Brasília, 2011.

COUTO, B. R. Formulação de projeto profissional de trabalho. In: CONSELHO FEDERAL DE SERVIÇO SOCIAL; ASSOCIAÇÃO BRASILEIRA DE ENSINO E PESQUISA EM SERVIÇO SOCIAL (Org.). Serviço Social: direitos sociais e competências profissionais. Brasília: CFESS/Abepss, 2009. p. 651-663. 
FERNANDES, F. A revolução burguesa no Brasil: ensaio de interpretação sociológica. 5. ed. São Paulo: Globo, 2005.

IAMAMOTO, M. V. Serviço Social na contemporaneidade: trabalho e formação profissional. 8. ed. São Paulo: Cortez, 2005.

. A formação acadêmico-profissional no Serviço Social brasileiro. Serviço Social \& Sociedade, São Paulo, n. 120, p. 609-639, out./dez. 2014. Disponível em: <http:// dx.doi.org/10.1590/0101-6628.001>. Acesso em: 10 jul. 2016.

LESSA, S.; TONET, I. Introdução à filosofia de Marx. 2. ed. São Paulo: Expressão Popular, 2011.

PEREIRA, L. D. Mercantilização do ensino superior, educação à distância e Serviço Social. Revista Katálysis, Florianópolis, v. 12, n. 2, p. 268-277, dez. 2009. Disponível em: $<$ http://www.scielo.br/scielo.php?script=sci_arttext\&pid=S1414-49802009000200017 $\& \operatorname{lng}=$ pt\&nrm=iso $>$. Acesso em: 27 fev. 2016.

PEREIRA, L. S. Estilos de aprender e ensino à distância: perfil de estudantes. Dissertação (Mestrado em Psicologia) — Programa de Pós-Graduação em Psicologia. Pontifícia Universidade Católica de Campinas, Campinas, 2007.

TONEGUTTI, C. A. Ensino à distância no Brasil: aspectos da realidade para estudantes e docentes. Universidade e Sociedade, Brasília, n. 45, p. 61-71, 2010. 